\title{
Psicossomática e contemporaneidade
}

\author{
Renan C. do Nascimento ${ }^{1}$
}

RESUMO - Esse artigo apresenta um resumo dos principais autores que contribuíram para a evolução conceitual do pensar psicossomático, privilegiando um recorte horizontal do conhecimento que relaciona a construção do sintoma psicossomático no contexto da contemporaneidade, com destaque para a reflexão psicanalítica acerca da construção e importância do sintoma.

Palavras-chave: psicossomática, sintoma, contemporaneidade, estresse, representação.

\section{Psychosomatic and contemporaneity}

\begin{abstract}
This paper presents a review of the most important authors that contributed to the conceptual evolution of the psychosomatic thinking, emphasizing the horizontal sequential evolution of the knowledge, associating the construction of psychosomatic symptom in the context of the Contemporary period, with prominence to psychoanalytic reflection about the construction and importance of the symptom.
\end{abstract}

Key works: psychosomatic, symptoms, contemporary, stress, representation.

O campo de estudos em Psicossomática encontra seara garantida no espaço da contemporaneidade, principalmente, pelo modo de vida contemporâneo, caracterizado por competitividade, sentimento de urgência e conflitos na construção do Eu. Considera-se que o campo de investigação psicossomático resulta da intersecção de duas grandes ordens: a informacional genético-cromossômica, e a edípica, as quais se intercambiam sem perder suas especificidades.

\footnotetext{
${ }^{1}$ Psicólogo clínico, mestre em Psicologia, especialista em Psicologia Hospitalar e Medicina Psicossomática, professor de psicofisiologia do UniCEUB, professor no curso de Formação em Psicossomática.
} 
A contemporaneidade, por sua vez, impõe "modo de viver" característico, marcado por exigência adaptativa padronizada pelo alto desempenho com baixo custo, inserido numa ordem social, na qual o sujeito é refém desse conjunto de expectativas, submetendo-o a um padrão de vida desconexo do sentido pelo qual se faz e se produz. Com efeito, as vicissitudes resultantes dessa intersecção resultam complexo padrão de sinais e sintomas, caracteristicamente psicossomáticos.

Contudo, no entendimento do conceito de psicossomática e de sua relação com a contemporaneidade, escolheu-se rastrear a construção conceitual por meio de autores e teses que contribuíram para o que se conhece atualmente, desde o período clássico, até os dias atuais, sobretudo, aquelas que promoveram reflexão nas relações mente-corpo, atravessando os irracionalistas, os chimpomorfistas, os maquinomorfistas, até os vitalistas, todos conforme a tendência dominante de sua época.

É, por assim dizer, em torno da consciência que gira essa discussão, pois, enquanto o cérebro é o maior desafio da neurofisiologia, a consciência é o maior desafio da humanidade. Assim, retoma-se a questão do pensar psicossomático como fator aglutinador e resultante dessas reflexões, imbricadas até os dias atuais, em várias áreas de conhecimento, o que possibilita a compreensão acerca da consciência e suas implicações somáticas, apesar das diferentes filiações teóricas.

Num recorte linearmente horizontal, inicia-se a provocação com Aristóteles (384 - 322 a. C), o qual utilizava o termo psiquê como princípio vital que é o ato ou perfeição do corpo organizado. Galeno (131 - 200 d.C), cuja influência perdurou até o século XIX, foi o primeiro quem observou a influência do humor em mulheres, relacionando-o com tumores, distinguindo-as entre melancólicas e coléricas, Já Galileu (1564 - 1642) considerava que a natureza era um sistema ligado a leis da matéria em movimento, e esse era o cerne de todas as coisas, em que tudo devia ter uma causa mecânica. Isso influenciou significativamente Descartes (Séc. XVI), o qual considerava os organismos como autômatos, que se formavam pelo encontro fortuito das partículas; a espécie humana diferir-se-ia por ter alma. Foi Descartes que propôs explicitamente o dualismo entre corpo e alma, adotando uma referência mecanicista. Com efeito, a problematização da relação entre mente e corpo encontra seu expoente mor em Descartes, ao inaugurar a subjetividade, o que possibilitou estudar as coisas da mente e as coisas do corpo. Essa postura considerava o organismo uma máquina, entendendo seus fenômenos como movimentos e forças, contrariamente aos vitalistas, que apontavam o organismo completamente controlado por uma alma sensitiva ${ }^{2}$.

${ }^{2}$ Apostila do Curso de Formação em Psicossomática - (Nascimento, 2002). 
Leibniz (1646/1715) traz a concepção de inconsciente e os graus de consciência, o que repercutiu, posteriormente, no pensamento freudiano e na elaboração da primeira tópica. Já com Emmanuel Kant (1724-1804), o sujeito é inserido como centro da teoria do conhecimento do homem, que comporta uma parte fisiológica, o homem e a natureza, e uma parte pragmática, o conhecimento produzido pelo homem.

François Bichat (1771-1802) desenvolveu a noção de sistema tissular funcional, baseado em estruturação de níveis de organização fisiológica dinâmica, em que as diferentes combinações promovem a desagregação ou a desorganização do organismo. E J.C. Heinroth (1818) introduz a palavra psicossomática na medicina, com o objetivo de designar doenças orgânicas provocadas por alterações mentais, sem, no entanto, explicitar essa conceituação. Citou o termo psicossomática em artigo que tratava da influência das paixões, no qual relacionava tuberculose, epilepsia e câncer com a importância da integração dos aspectos físicos e anímicos do adoecer. Posteriormente, criou o termo somatopsíquico, designando transtornos psicológicos decorrentes do fator somático. Assim, sua atenção residia na etiologia do sintoma e, não, no mecanismo de construção do sintoma.

A Teoria de Haeckel (séc. XIX), acerca da recapitulação observa que um organismo, durante a sua ontogênese, passa por todos os estágios morfológicos dos seus ancestrais, o que originou a embriologia comparativa. Outro teórico importante foi Claude Bernard (1840), que introduziu o conceito de meio interno e constância desse meio, o que possibilitou ampliar os estudos na fisiologia celular. Charles Darwin (1859) inova com a origem das espécies e a teoria da evolução; por volta do ano de 1861, publica o que seria o primeiro livro sobre a biologia das emoções: As emoções no homem e nos animais. Por outro lado, William James (1860), retoma a questão da consciência, considerando-a mutável, pessoal, individualista, como um processo; evidencia os limítrofes da consciência: a unidade biológica da consciência, as funções adaptativas da consciência; considera os hábitos involuntários versus escolha consciente.

Encontramos, em Sigmund Freud (1900), a principal caracterização da estrutura do aparelho psíquico em sua tópica, que apresenta os seguintes aspectos: o inconsciente e o seu funcionamento, a relação entre conversão histérica e conflitos sexuais, a noção de sintoma com base na idéia do recalcamento e a arquitetura e o funcionamento anímico. "A interpretação dos sonhos", é resultante de seu trabalho anterior - "Projeto" (1895), no qual abordava, nitidamente, o ponto de vista biológico, a dor, a consciência, o problema da quantidade, da qualidade, o funcionamento do aparelho, a experiência da satisfação, os afetos e os estados de desejo, os processos primários, a noção de ego, a memória, o juízo.

Freud apresentou o primeiro conceito de somatização em "Cinco lições de psicanálise"(1915), em que menciona a palavra, designando-a como o resultante 
dos conflitos do desejo frente à barreira do recalcamento, que adquiririam formas de manifestação somática em sua natureza simbólica. Com a somatização, a ansiedade era diminuída, daí a importância do simbolismo na sintomatologia. Freud (1925) apresenta importante conceito que direcionaria, posteriormente, os rumos da psicossomática: pulsão ou instinto (trieb), a fronteira entre o somático e o mental, representante psíquico das forças orgânicas.

Contemporâneo á Freud, Groddeck (1930) retoma a noção do simbólico, concomitantemente à apresentação do conceito do "isso" como organizador vital. Seu modo de proceder partia do princípio de que as doenças do homem eram uma espécie de representação simbólica de suas predisposições psicológicas. Groddeck recusava a aceitar a diferença entre alma e corpo em dois compartimentos. No monismo de Groddeck e no dualismo de Freud, apesar do antagonismo vetorial, encontramos as noções precursoras da psicossomática com revolucionário modo complexo de pensar a doença e a saúde. Groddeck via, na doença, um processo criativo, em que ponderava a necessidade de diminuir o peso do diagnóstico, em benefício do conhecimento mais íntimo do doente, de sua problemática e de seu sofrimento. Freud contribuiu com a relevância da representação, seu papel na construção do ego e seus recursos na formação de sintomas.

De acordo com a perspectiva neurofisiológica, Walter Cannon (1932), apresentou o conceito de homeostasia, a tendência dinâmica de os organismos vivos manterem as diferenças, ou seja, a tendência ao equilíbrio, e o conceito de reação de emergência, o padrão de resposta "fight or flight". Esses conceitos influenciaram H. Seyle (1936) posteriormente, em relação à teoria da síndrome da adaptação geral (SAG), conhecida como "stress", na qual explicitava a capacidade adaptativa do organismo, por meio de fases: alarme, resistência e exaustão; ele considerava a organicidade fisiológica e psíquica como padrão adaptativo. Na mesma década, Papez (1937) propõe a afirmativa de que a experiência mental é transduzida por meio de excitabilidade emocional pelo sistema límbico-hipotalâmico e estruturas correlatas, relacionando alterações funcionais no sistema límbico com mudanças emocionais.

Por outro recorte, os estudos em psicossomática tornam-se mais difundidos com os trabalhos de Helen Flanders Dunbar (1940), que relatou mais de dois mil casos clínicos nos quais relacionava doença e traços de personalidade, definindoos como doenças psicossomáticas. Discípulo de Dumbar, surge Franz Alexander (1950) com a publicação de Medicina psicossomática, o qual abordava os distúrbios psicossomáticos de acordo com estados emocionais específicos como geradores de distúrbios específicos, adotando uma relação de perfil de personalidade na gênese da patologia ${ }^{2}$.

${ }^{2}$ Idem 
Jacques Lacan (1953) retoma a leitura em Freud e evidencia a importância da palavra no entendimento da doença e na orientação para a cura. "A psicanálise só

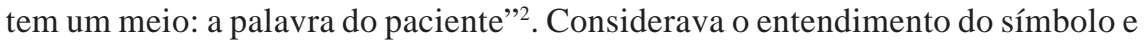
a linguagem como estrutura e limite do campo psicanalítico. Destacava a relação entre significado e significante, ambos ocorrendo como barreira resistente à significação - um significante é o que representa o sujeito para outro significante. Com base neste pressuposto, o sintoma é definido como uma formação do inconsciente, com uma estrutura de linguagem própria, efetivada a partir de metáforas, sendo passíveis de deslocamento e re-significação. Assim, a doença e o adoecer expressam a maneira de uma pessoa viver e sua relação com o universo que o cerca.

Michel Foucault (1972), em "História da loucura", constitui pertinente provocação dirigida aos interditos da medicina para com o sujeito, no qual retrata que o conhecimento da doença deve fazer o inventário de tudo o que existe de mais manifesto na percepção, de mais evidente na "verdade". Assim, define como procedimento primeiro da medicina o método sintomático que toma emprestadas as características das doenças, dos fenômenos invariáveis e dos sintomas evidentes que as acompanham, para ter entendimento mais amplo do sujeito e não do organismo.

Niels Jerne (1974), prêmio Nobel, elaborou modelo conceitual denominado "teorias de rede" para explicar as complexas ligações entre antígeno e anticorpo, nas quais o sistema imune seria o mediador do indivíduo consigo mesmo e com o seu meio. Posteriormente, Glaser, Kiecolt, Khansari (1989) evidenciam a estreita relação dos efeitos do estresse na atividade imunológica, na qual a resposta a ele dá-se por meio da ação integrada dos sistemas, num processo de alteração e recuperação da homeostasia a todo instante. Reproduzem os achados de Friedman, Glasgow e Adler (1969) que constituíram uma base experimental na compreensão das complexas interações entre estresse e neoplasias, produzidas em laboratório.

Pierre Marty (1984), da escola francesa, apresenta dois conceitos importantes: depressão essencial e alexitimia, considerados como forma de empobrecimento das estratégias psíquicas, que favorece o aparecimento de sintomas psicossomáticos. Conclui que a psicossomática impõe "novo velho" modelo de pensar o sujeito com base em sua totalidade, compreendendo suas especificidades. Neste cenário da contemporaneidade, encontra-se contínua mudança nas manifestações psicofisiológicas, com derivações típicas do indivíduo pós-moderno resultantes de seu modo de enfrentar o estresse, o que gera uma requintada arquitetura do adoecimento, isto é, processos psicossomáticos. O recorte psicanalítico de Pierre

\footnotetext{
${ }^{2}$ Idem
} 
Marty na psicossomática marca, definitivamente, a evolução das concepções acerca das relações entre o psíquico e o somático, por considerar a noção de representação como a coisa dotada de sentido e significação baseada na alteridade.

Outra importante contribuição é de Sapolsky (1989), que propôs reformulação da teoria do estresse de Selye, em que se abre a possibilidade de retomar a noção básica de psicossomática, o processo complexo de somatização, por meio de mecanismos informacionais. Divide o S.A.G. em duas fases: resposta adaptativa complexa de ativação e alarme; conseqüências do desajuste da resposta de estresse prolongado quando a ativação se torna crônica. Esse caminho procura ver de perto os detalhes, reconstituir a doença com a exatidão de um retrato. Tom Stonier (1990) descreve a base informacional e considera que a informação é o princípio organizador do universo, em todos os níveis, possuindo status semelhante ao da matéria e da energia.

De acordo com o conjunto de saberes postulados anteriormente, observase o aspecto multidisciplinar que gira em torno da psicossomática, isto é, o pensar psicossomático não se restringe a nenhuma filiação teórica específica, contudo resulta de integração interdisciplinar, de um conjunto de saberes, o que comporta um modo de escuta diferenciada em torno da doença.

A descoberta da função da sexualidade na etiologia das neuroses não foi apenas um resgate efetuado por Freud, da dimensão da existência humana culturalmente acobertada. Permitiu, também, outra visão do desenvolvimento do ser humano, sobretudo das experiências infantis, além de colocar em evidência a existência de um tipo de energia, a libido, ao mesmo tempo em que é essencial e ameaçadora para a existência humana. Enraizada no organismo, a excitação sexual ocupa lugar fundamental na estruturação do aparelho psíquico, bem como na polarização dos conflitos aos quais estará submetido.

Assim, o modelo freudiano é marcado, desde suas primeiras formulações, pela dimensão econômica que busca compreender os destinos da excitação sexual no organismo e sua relação com outras funções da existência. Revela as condições em que essa excitação pode ou não ser satisfeita, como se desenvolve por meio das diferentes etapas (oral, anal, fálica e genital) e como tem acesso á consciência mediante representação ou quando o acesso é impedido pelo recalque. Dessa forma, a construção do sintoma psicossomático estará diretamente vinculada a cada etapa específica do desenvolvimento, em que todos os sintomas terão sua fase pré-edípica, baseada na representação específica de cada fase e não apenas pelo sintoma em si.

Essas dinâmicas e seus desdobramentos são, desde o início, moldados pelas relações do sujeito com outro humano, o caráter alter; é no âmbito dessa relação 
que se delineia a primeira experiência de frustração e ou de satisfação das necessidades corporais da criança. Como revelou Freud, é sobre essas primeiras experiências ligadas às necessidades, como fome, sede, limpeza, calor, proteção, que se apóiam e se estruturam as experiências de prazer, marcando a passagem da ordem do instinto para a da pulsão e do funcionamento biológico para a organização erógena e subjetiva do indivíduo.

Com efeito, o destino da excitação sexual é marcado pelas experiências de satisfação ou de frustração experimentadas pelo sujeito tanto em relação a outro humano, o objeto externo, como no próprio corpo do sujeito por meio das experiências auto-erógenas. No capítulo VII de "A interpretação dos sonhos", Freud apresenta a primeira tópica, em que concebe a noção das três instâncias: inconsciente, préconsciente e consciente, cujas dinâmicas internas determinam as condições de acessibilidade de experiências, recordações, representações ao conhecimento do sujeito.

Nessa concepção, o pré-consciente ocupa lugar de destaque na compreensão da dinâmica psíquica e, em particular, na articulação do inconsciente. O préconsciente (Pc) situa-se como passagem incontornável de qualquer representação psíquica rumo á consciência e constitui verdadeiro reservatório de representações. Estas, ao mesmo tempo em que são passíveis de acesso à consciência, preservam certa proximidade com as fontes somática, pulsionais e instintivas. Nesse sentido, o (Pc) constitui um operador de ligações psíquicas e de comunicação entre as instâncias, que, segundo P Marty, a fluidez da circulação entre as três instâncias do aparelho anímico é fator essencial ao equilíbrio psicossomático.

Segundo esse modelo econômico, a ligação entre representação e afeto é condição para que uma idéia, uma sensação e uma experiência possam ser objeto da consciência. O afeto, ou excitação, porém permanece livre, desligado. Por sua essência, busca descarga ou ligação; pode tanto ligar-se a outras representações como descarregar-se por meio de funções corporais ou de comportamentos.

No âmbito da teoria freudiana, sabemos que a ligação do afeto desinvestido pelo recalque em representação substitutiva caracteriza o mecanismo de deslocamento, a dinâmica central da neurose e das fobias, e a ligação e a descarga desse afeto por meio de partes do corpo configuram o mecanismo da conversão, característico das manifestações histéricas. Tanto um como o outro designam o corpo como representante legítimo da materialização dessas pulsões, o que explica o ponto de vista dinâmico e econômico da somatização.

É no espaço da contemporaneidade que o sujeito encontra, no sintoma, o modo de justificar-se perante o outro, evidenciando limites, incapacidades, desejos e escolhas. Nesse contexto, o mecanismo transdutor das representações 
substitutivas e da ligação e descarga do afeto em distúrbios psicossomáticos residem no estresse, no modo como o sujeito o interpela, sobretudo pela desconstrução do $e u$, por meio de exigências contemporâneas que promovem aumento na carga diestressora, resultando em transtornos psicossomáticos. Assim, o viver na contemporaneidade configura o estresse como a mecânica transdutora dos distúrbios psicossomáticos.

A consideração de Stonier acerca da organização do universo por meio da informação faz-nos crer que toda tensão psíquica contém padrões informacionais que serão transformados em correspondente tensão cerebral, o que resulta em excitabilidade neurofisiológica compatível com a excitabilidade mental inicial, consciente ou inconsciente. Esta é, por assim dizer, transduzida em excitabilidade corporal compatível com a inicial, ou seja, a angústia ou medo, a excitação psíquica, são transduzidos em excitação límbica, de hipotalâmica para hipofisária, por meio de moléculas mensageiras, os hormônios neurotransmissores, que partem do hipotálamo para a hipófise e, desta, para outras glândulas: tireóide, timo, suprarenais. Assim, a contração do córtex da supra-renal, por exemplo, secreta catecolaminas e córtico-esteróides que traduzem a informação psíquica inicial, medo ou angústia, que é levada a outras partes do corpo, tais como, o fígado, o coração, os músculos, também por meio de outros hormônios, as moléculas mensageiras, como em cadeia específica informacional.

É por este mecanismo que compreendemos como e o porquê o coração acelera mediante a presença de representação incompatível, a ligação do afeto desinvestido, mesmo inconsciente, isto é, a pessoa apresenta desconforto cardio-respiratório, mesmo sem saber, ao certo, o porquê disto. Com o passar do tempo, esses caminhos informacionais criam memória somática do sintoma utilizada segundo a conveniência inconsciente do sujeito.

Assim, é por meio de representações, a apresentação psíquica de uma necessidade somática, dotada de sentido por meio de outro, que o sujeito significa o simbolismo de seu sintoma, desde a construção histérica, até o padrão neurótico de somatização, seja por deformação e/ ou construção da auto-imagem real ou imaginária. $\mathrm{O}$ modelo representacional promove a tentativa de articulação entre os modelos biológico e mecânico e o inconsciente, possibilitando explicar as complexas operações do pensamento.

Com efeito, a construção do mecanismo psicossomático ganha materialidade por meio da conversão, a transformação de representação incompatível em sintomas dotados de simbolismo específicos ao sujeito, ou por meio da construção de um sintoma, o resultado dos conflitos entre as representações, com deslocamento do afeto referente a representação incompatível para a representação substituta. $\mathrm{Ou}$ seja, o processo de excitação o qual não encontrou descarga adequada origina 
um produto anormal - o sintoma - que, como corpo estranho, insinua-se no estado normal. É na existência do sintoma que há também amnésia, uma lacuna da memória, cujo preenchimento suprime as condições que conduzem a formação do sintoma ${ }^{5}$. A substituição da idéia reprimida pelo sintoma é protegida contra as forças defensivas do ego, e, em lugar do conflito psíquico, há extenso sofrimento somático.

Como resultado da construção do sintoma, a materialização psicossomática, a angústia e a ansiedade são diminuídas; daí, concebe-se a importância do simbolismo na sintomatologia por caracterizar-se como o caminho de resolução do conflito psíquico. Pois, o sintoma é dado como formação do inconsciente, com estrutura de linguagem própria, efetivada de acordo com metáforas, passíveis de deslocamento e cura por meio da re-significação.

\section{Referências}

FILHO, Carlos U. J. Corpo-mente: uma fronteira móvel. São Paulo: Casa do Psicólogo, 1995.

FREUD, S. Sobre o narcisismo: Uma introdução. E.S.B. XIV. Rio de Janeiro: Imago, $1914-1996$.

—. A interpretação dos Sonhos. E.S.B. IV.Rio de Janeiro: Imago, 1900 - 1996.

FOUCAULT, M. História da loucura. Graal, 1972.

GLASER, R. \& KIECOLT - GLASER, J. Modulation of the cellular immune response. Clinical Immunology Newsletter - 11, 1991.

GRODDECK, G., O livro dISSO, São Paulo: Perspectiva, 1984.

LIMA, A S., Pulsões uma orquestra psicanalítica no compasso entre o corpo e o objeto, Ed Vozes, Petrópolis-RJ: 1995.

NASIO, J D., Psicossomática as formações do objeto a. Rio de janeiro: Jorge Zahar, 1993.

MARTY, P. A Psicossomática do adulto. Porto Alegre: Artes Médicas, 1993.

—. Mentalização e Psicossomática. São Paulo: Casa do Psicólogo, 1998.

NASCIMENTO, R.C. A noção de representação nos escritos iniciais de Freud e a construção de um novo modelo do psíquico. Dissertação de Mestrado apresentada na Universidade Católica de Brasília, Distrito Federal, 2001.

—. Apostila do Curso de Formação em Psicossomática - teoria e vivência, Brasília-DF: 2002.

OLIEVENSTEIN C., O não-dito das emoções, Ed Jorge Zahar, Rio de Janeiro, 1989. 
PIMENTEL D., O estatuto do corpo e os fenômenos psicossomáticos, Revista da Associação Brasileira de Medicina Psicossomática - Vol. 3 maio de 1999.

ROSSI, EL., CHEEK, D B., Mind-body therapy, Methods of Ideodinamic Healing in Hypnosis. New York: W W Norton e Company, 1994.

ROSSI, E L., A psicobiologia da cura mente-corpo. Campinas: Editorial Psy, 1994.

SAMI-ALI, Pensar o somático e o imaginário e patologia. São Paulo: Casa do Psicólogo, 1995.

SAPOLSKY, R., Neuroendocrinology of the stress response. In: BECKER, J.; BREEDLOVE, S.; CREWS, D. (Eds.). Behavioral Endocrinology. Cambridge: MIT Press, 1992.

VOLICH, R. M. Psicossomática - clínica psicanalítica. 2. ed. Rio de Janeiro: Casa do Psicólogo, 2000.

WINTER, T. R. O enigma da doença-uma conversa á luz da psicossomática contemporânea. Rio de Janeiro: Casa do Psicólogo, 1997. 